\title{
4. PRESENTATION OF RANGER VII MOON IMAGES
}

\author{
G. P. Kuiper and E. A. Whitaker \\ (Lunar and Planetary Laboratory)
}

Le Prof. G. P. Kuiper commente dans leurs détails la série des clichés obtenus; il annonce la préparation d'un Atlas d'environ 200 clichés lunaires obtenus avec la chambre $f: 1$ de $25 \mathrm{~mm}$ de Ranger VII. Cet Atlas aura deux éditions, l'une comportant des planches imprimées, l'autre des reproductions photographiques.

Le dernier cliché correspond à une altitude de 300 mètres au-dessus de la surface lunaire. Avec la chambre $f: 2$, ce cliché et le précédent ont une résolution sur la surface lunaire de l'ordre de 25 et $40 \mathrm{~cm}$ respectivement, cependant que le dernier cliché obtenu avec la chambre $f: \mathrm{I}$ a une résolution d'environ 8 mètres. Des cratères d'un mètre de diamètre et de quelques décimètres de profondeur, sont observés. Le point d'impact se trouve sur une des structures radiales issues du cratère Tycho.

Le Prof. G. P. Kuiper présente en conclusion le film obtenu par la succession des clichés de la surface lunaire. Ce film, en une bande de 3 minutes de durée, rassemble les images consécutives obtenues avec la chambre $f: \mathrm{I}$ de la fusée; la projection de chaque image y occupe une seconde de temps. Le film montre d'une façon particulièrement frappante l'approche de la surface lunaire. Les cratères, collines, failles s'accentuent progressivement, cependant que deviennent visibles, dans cette chute rapide vers la Lune, des détails inobservables de la Terre. Des applaudissements nourris montrent à quel point ce film a rendu manifestes les progrès accomplis dans la connaissance du sol lunaire grâce à Ranger VII.

Ces données seront publiées plus complètement dans la presse astronomique.

On trouvera ci-après les conclusions du Dr Kuiper, telles qu'elles apparaissent après le vol plus récent de Ranger VIII; le Secrétaire Général de l'UAI est reconnaissant au Dr Kuiper d'avoir rédigé ainsi un texte modernisé (voir aussi Science, in press).

\section{THE SURFACE OF THE MOON}

\section{G. P. Kuiper \\ (Lunar and Planetary Laboratory)}

With two of the three Ranger VII atlases now published (x) and the Experimenters' Report in press, and with the Ranger VIII mission sucessfully accomplished, time may be opportune to summarize some of the scientific results and tentative explanations arrived at. This note is not an official report and the interpretive views are my own, based largely on work done at this laboratory in collaboration with Messrs. E. A. Whitaker and R. G. Strom.

It has been our first concern to ensure that the magnificent Ranger records be published as completely as possible, the only limitation being the elimination of entirely unnecessary redundacy; and that the published records reproduce the full image content. Much time and thought has been given to this publication problem and Whitaker has applied his full skill in the production and supervision of the photographic editions.

The interpretive work has relied heavily on our collection of plates built up since 1959 at the McDonald 82-inch and the Yerkes 40 -inch telescopes. This work includes a high-resolution study of the color distribution over the lunar surface by Whitaker, with photoelectric calibrations by Dr Gehrels. The color study has shown that the Moon is not covered with a layer of cosmic dust which would have obliterated the color differences; and that any migration of a 
hypothetical layer of lunar dust is restricted to subtelescopic dimensions because the color provinces observed have extremely sharp boundaries. Instead, the lunar surface materials such as crater rays and structures such as the prominent flows observed on Mare Imbrium and Mare Serenitatis, each have characteristic colors, often quite uniform over a single feature, though adjacent structural features may differ markedly. The Earth-based photographs make plain that the lunar maria were built up as a succession of flows (presumably lava); each flow having distinct terminal walls and therefore having had a very viscous or solid outer surface during deposition; and yet, being very extended, up to $200 \mathrm{~km}$ in length, on surfaces sloping about $\mathrm{I}^{\circ}$ or less, having a highly fluid interior at the time of deposition. The observed flows are 50-200 $\mathrm{m}$ thick but thinner flows may exist. On the basis of experiments with liquid silicates in vacuo and on certain rock formations found on Hawaii (materials thrown out of Laimana Crater in 1960 in liquid form and solidified in free fall) it is concluded that the flows observed on the lunar maria were originally covered by a layer of roughly ro $\mathrm{m}$ thick of extremely vesicular rock, with a bulk density of $0 \cdot 1-0 \cdot 3$, and a bearing strength of the order of $I-1 \circ \mathrm{kg} / \mathrm{cm}^{2}$. Below this surface layer a denser rock is expected to exist having resulted from solidification of the very fluid magma responsible for the bulk of the flow. A succession of flows, as observed on Mare Imbrium, will have led to an alternation of vesicular and denser layers.

I. A comparison of the last A and B frames of Ranger VIII, released on the day they were obtained, 20 February 1965, with the last A and B frames of Ranger VII, released on the day they were obtained, 3 I July 1964, shows a remarkable similarity of the two maria, in spite of their appreciable color differences. Both show an abundance of very shallow dips of a variety of dimensions and depth-to-diameter ratios. Diameters of $50-100 \mathrm{~m}$ and depths of $\mathrm{I}-1 \mathrm{O} \mathrm{m}$ are seen to be typical. These shallow dips show no sign of explosive violence; the slopes are extremely smooth, somewhat like an inverted gaussian curve rotated around its vertical axis of symmetry. The deeper depressions show signs of breaks in the walls; and some depressions end not in a flat round bottom but in a point of a short horizontal line. These pointed depressions look somewhat like dimples and they might suggest drainage to subsurface cavities; but this does not explain their round shoulders, which are indistinguishable from those of depressions without the funnel.

The fact that both maria show these depressions and that the lower Sun angle of the Ranger VIII records $\left(15^{\circ}\right.$ versus $23^{\circ}$ ) allows us to see them over the entire surface, suggests that a general property of a mare surface is involved. One might at first suppose that this structure could be explained by a surface heavily cratered by post-mare impacts and subsequently buried by dust. But this is most unlikely on several grounds: $(a)$ no single thickness can explain both the large and small dimple craters of similar proportion, and the shallow and deep depressions; $(b)$ fine fractures (scale $\sim \mathrm{I}-2 \mathrm{~m}$ ) are observed that are structurally related to the depressions in a manner suggesting a brittle rock surface; $(c)$ lineaments are observed over the entire mare surface to the smallest resolved dimension, apparently part of a global lineament pattern (see below); $(d)$ an observable cosmic dust layer on the lunar surface is absent (see above) and the part-mare impact rate of particles below $10^{4} \mathrm{~g}$ is about $\mathrm{I} \mathrm{g} / \mathrm{cm}^{2} / 4^{\cdot} \cdot \mathrm{O}^{9}$ years (2).

Instead, one appears to observe here a karst-type formation, which it closely resembles in appearance and scale (3). There are three causes that would have led to karst-type depressions on the lunar maria: $(a)$ the relocation or even local drainage of magmas below the surface rock-froth layer; $(b)$ the volume decreases of the subsurface materials resulting from solidification and cooling; $(c)$ the escape of gases. These three mechanisms are the equivalent of solution of subsurface limestone in the karst formations. Cave-ins of the ceilings of cavities will lead to dimple craters. On the basis of the above identification the sink holes and dimple craters are early post-mare in age. The absence of an appreciable straight conical section on the slopes 
of the dimple craters indicates that drainage of surface materials into the holes has been small. This is consistent with the other observations of the mare surface bearing on the question of the presence of loose or displaced surface materials (the fine lineaments observed indicate that such materials are less than $2 \mathrm{~m}$ thick).

2. A second phenomenon discovered and interpreted on the basis of Ranger records is the fine structure of crater rays. While major rays were intentionally avoided in both missions because of their known disruption to the lunar surface, Ranger VII did impact in a small and weak Tycho ray, with another Tycho ray element close enough to be adequately resolved also. Generalizing from these data and after a re-examination of the best Earth-based records of the Tycho rays, we may say that each major crater ray is composed of many elements, each of which appears to start with a secondary impact crater or a cluster of such craters, from which issues a separate ray element in the direction away from Tycho. Whitaker has pointed out that this observation is most readily explained if the Tycho explosion itself caused a blast over the lunar surface that blew the fine debris caused from the secondary impacts downwind, away from the central crater. In order that this blast persist for the flight time of ro-30 minutes (Mare Cognitum is $1000 \mathrm{~km}$ away, $v \cong I \mathrm{~km} / \mathrm{sec}$ ) it may be assumed that low-temperature volatiles were involved; sublimated particles would not be an effective force for deflecting the ray elements. This leads to the hypothesis that ray craters, such as Tycho, were tormed by the impact of a comet, an assumption previously made by H. C. Urey and E. A. Whitaker. A comet would also appear to be a suitable source of the materials causing the bright secondary impact craters or clusters of such craters at the head of each ray element; because they seem to be of different composition from the ejecta that formed the thousands of secondary craters much nearer to Tycho that have no ray elements associated with them. The latter were presumably formed by lunar debris, as was the case for the very numerous secondaries found around all other major post-mare craters, regardless of the presence of rays.

3. A third phenomenon, known before but interpreted on the basis of the Ranger records, is that of the mare ridges (sometimes called wrinkle ridges). Through a fortunate accident one ridge in Mare Cognitum, which had been dissected by an impact crater, was well observed by Ranger VII. It became apparent that the following model satisfies the observations. The ridges are strips of the lunar mare crust uplifted and during this uplift sometimes broken, by dikes that form in subsurface fissures. These fissures have formed as a result of dynamical causes, either encompassing the entire Moon (related to the global grid system) or restricted to a basin (radial and peripheral ridges in maria, etc.). Where ridges have broken the mare surface, the dikes are observable as light-colored walls, some 50-100 m wide, protruding up to $10-20 \mathrm{~m}$ above the surroundings. The ridges and dikes frequently exhibit en échelon structure, apparently caused by subsurface branching of the fissures, with sometimes as many as four parallel branches approaching the surface.

4. A fourth phenomenon, also known before, that has been clarified by the Ranger records, is that of the rilles often found just within the shorelines of a mare. From Earth-based observations these had been identified as graben (4). The Ranger VIII photographs released show the correctness of this description, including the en échelon nature of these rilles.

5. A fifth, most important, aspect, is that of the lineaments. Mr R. Strom of this laboratory has made an analysis of these and has found the fine linear structures, so well portrayed in the five ACIC maps of the Ranger VII area (scales I:I $000000 ; 500000$; 100000 ; 1000; 350) mostly belong to a global lineament system recently investigated (5). From the visibility of these five lineament structures Strom has estimated that any layer of displaced debris scattered on the original igneous surface will be less than $2 \mathrm{~m}$ thick.

6. A sixth result of importance is the frequency of lunar craters below the I $\mathrm{km}$ limit set by the best telescopic surveys. Crater counts have been made under Dr E. Shoemaker's direction 
at the Astrogeology Branch of the Geological Survey, and also by W. K. Hartmann at this laboratory. There is good evidence that the slope defined in a $\log N$ versus $\log D$ plot of about -2 , found for the telescopic craters on the maria, continues for the smaller primary craters down to the meter size, in agreement with theoretical predictions from data for asteroids and meteorites, assumed to be largely responsible for the primaries; and that a bulge observed in the frequency curve near $D=25 \circ \mathrm{m}$, is due to secondaries that could not be avoided in the regions covered by the crater counts. The primaries down to the meter range cover roughly i per cent of the mare surface. Secondaries are especially numerous in the crater rays; their over-all distribution around the various major post-mare craters is not yet known in any detail, and the distinction between secondary craters, sinkholes and dimple craters will present problems.

7. The seventh item of interest is the presence or absence of loose rocks on the lunar surface, the maria in particular. The apparent absence of such rocks on the Ranger VII records has evoked much comment. It seemed in stark contradiction to the numerous secondary impact craters evidently caused by ejected rocks. I believe this reaction stemmed from seeing too close an anology with terrestrial conditions. The smallest observable rocks will be about $\mathrm{I} \mathrm{m}^{3}$. If their mean bulk density is unity (because of cavities) and if the bearing strength of the mare surface for static loads is indeed about $4 \mathrm{~kg} / \mathrm{cm}^{2}$, such rocks will not sink into the surface if put there gently (required bearing strength $\mathrm{I} 7 \mathrm{~g} / \mathrm{cm}^{2}$ ); but if tossed into Mare Cognitum from 'Tycho, they would penetrate the surface hundreds of times the rocks' diameter, if the subsurface rock were as fragile as the surface rock. The rock would remain visible only if $v<20$ $\mathrm{m} / \mathrm{sec}$ or its source less than $25^{\circ} \mathrm{m}$ away. Actually, on the inner wall of the large crater (wall diameter $450 \mathrm{~m}$ ) shown on the last B frame of Ranger VIII several rocks are shown about 3-5 $\mathrm{m}$ in diameter, the only ones so far identified on the Moon. One of them appears on the rim of what may be a secondary crater, $5 \mathrm{~m}$ in diameter. Conceivably these rocks could come from a distance in excess of $250 \mathrm{~m}$ because they may have been stopped by a stronger rock layer at this depth (about 5-10 $\mathrm{m}$ ) below the original lunar surface.

8. The structure of the mare floor in the meter and submeter range is a long-standing problem. Ranger VII has shown that there exists a tree-bark pattern with the raised elements typically Io-30 $\mathrm{m}$ long, $5^{-1} 5 \mathrm{~m}$ wide, $\mathrm{I}-2 \mathrm{~m}$ high. This pattern appears somewhat soft, suggesting erosion in the $0.5^{-1} \mathrm{~m}$ scale. It is not quite clear at this time whether this pattern is entirely due to the original lava deposit or in part to cracking and local subsidence resulting from the karst-type phenomenon described.

9. Mountain ridges known from telescopic observation were shown to be volcanic in origin, along structural lines marked in part by ridges (see above). Often small calderas are found on the crests of these ridges. It is fair to say that the Ranger data have solved or probably can solve many basic problems attending mare formation. O'Keefe (6) has pointed out one convincing example of post-mare volcanism on the Ranger VII records.

I0. The highlands or terrae are not considered here because Rangers VII and VIII show with highest resolution selected mare districts. There is much to be learned on the terrae also, however, especially from the stereo coverage that the new data provide; Ranger VII (B camera) combined with Earth-based records; Ranger VIII A versus B and Earth-based.

One further consequence of the Ranger missions will be that it has provided many clues to interpreting Earth-based plates; and has enhaced their value for the study of regions not covered by Ranger.

\section{REFERENCES}

r. Ranger VII photographs of the Moon, Part I: Camera "A" series, JPL, 27 Aug. 1964; GPO edition Sept. 1964; Part II : Camera "B" series, JPL, 15 Dec. 1964; GPO edition Jan. I965; Part III : Camera "P" series, In preparation. 
2. McCracken, C. W., Dubin, M. "Dust Bombardment on the Lunar Surface" NASA Tiv D-2100, 1963; also in Lunar Surface Layer, Materials and Characteristics. Eds. J. W. Salisbury and P. E. Glaser, Academic Press, New York, pp. I79-214, 1964.

3. Thornbury, W. D. Principles of Geomorphology. Wiley, New York and London, pp. 32 I ff, I954.

4. Kuiper, G. P. "The Exploration of the Moon", Vistas in Astronautics. Pergamon Press, vol. 2, section C, p. 303 , 1959 .

5. Strom, R. G. Comm. Lunar and Planetary Laboratory, no. 39, I964.

6. O'Keefe, J. A. Science, 146, 5I4-5I5, I964.

\section{INTERPRETATION OF THE SMALL CRATERS OF THE MOON'S SURFACE REVEALED BY RANGER VII}

\section{E. M. Shoemaker}

(U.S. Geological Survey, Flagstaff, Ariz., U.S.A.)

The small topographic features revealed by the Ranger VII photographs of Mare Cognitum are almost all craters. Craters thus are not only the dominant large topographic features on the Moon but also the dominant small topographic form revealed by Ranger VII. The newly observed craters are of many shapes. Some may be recognized as belonging to certain classes of craters observed through the telescope, but many less than $300 \mathrm{~m}$ across cannot be classified by shape alone in the categories previously recognized by telescopic observations.

\section{Shapes of craters}

Two basic types of craters well known from telescopic observations can be readily identified in the Ranger photographs: ( 1 ) primary craters and (2) secondary craters.* These types are defined on the basis of morphology and distribution. Small telescopically observable primary craters are typically uniform in shape. They are nearly circular and have a distinct, smooth, raised rim, generally of nearly uniform height. The inner walls are smooth, uniform, steep, and slightly concave upward. Typical slopes of the wall near the rim crest are greater than $35^{\circ}$ and, near the foot, about $25^{\circ}$. In primary craters larger than about $7 \mathrm{~km}$ in diameter, the steep wall terminates against a relatively smooth, level, circular floor. The diameter of the floor diminishes with size and is very small or absent in primary craters less than $7 \mathrm{~km}$ across; the walls thus extend to the center or almost to the center of these small craters. As Kuiper has remarked (r), these remarkably uniform craters look as though they had been turned out on a lathe. They are scattered across the maria and other parts of the Moon without apparent control by other surface features. Some of them are surrounded by a bright halo, or a system of rays; others are not.

With increased diameter, the primary craters are less regular in form. At $25 \mathrm{~km}$ diameter, some irregular hummocks are found in the rim, terraces occur on the crater walls, and irregularities begin to appear on the floor. At 50 or $60 \mathrm{~km}$ diameter, the rims are typically rugged and hummocky, the rim crest is uneven and commonly roughly hexagonal in plan, the walls are terraced, and the floor is marked by scattered hills and one or more prominent irregular peaks near the center of the crater. A swarm of small craters, which are barely resolvable through the telescope, surrounds a primary crater of this size.

* Other classes of craters known from telescopic observations, such as chain craters and craters at the summits of domes, are apparently not represented in the high-resolution Ranger VII photographs and will not be discussed in this report. 